\begin{tabular}{l} 
DE DE GRUYTER \\
\hline
\end{tabular}

\title{
IMPROVEMENT POSSIBILITIES OF HETEROGENEOUS PHOTOCATALYSIS WITH THE AIM OF IN-FIELD USE
}

\author{
Orsolya Fónagy, ${ }^{1}$ Péter Hegedüs, ${ }^{1}$ Erzsébet Szabó-BÁrdos, ${ }^{1}$ Annamária dobrádi, ${ }^{2}$ \\ AND OTTÓ HORVÁTH ${ }^{*}$ \\ ${ }^{1}$ Department of General and Inorganic Chemistry, University of Pannonia, Egyetem u. 10., H-8200 \\ Veszprém, HUNGARY \\ ${ }^{2}$ Institute of Materials Engineering, University of Pannonia, Egyetem u. 10., H-8200 Veszprém, \\ HUNGARY
}

\begin{abstract}
Heterogeneous photocatalysis can be successfully applied for the degradation of organic pollutants, although the efficiency of this method is insufficient. It can be increased by modification of the catalyst with precious metals (e.g. silver) or heterogeneous catalysis can be combined with other oxidative procedures such as ozonation. Another obstacle to the infield use of the method is that separating the catalyst from the liquid phase is difficult. This problem can be

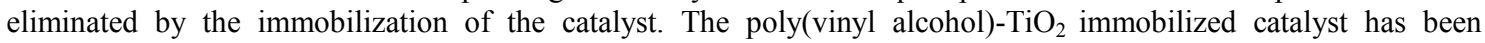
prepared for this purpose. During $\mathrm{TiO}_{2}$-based photocatalysis, active oxygen species such as the hydroxyl radical, superoxide radical and hydrogen peroxide are produced. The formation rate of the oxidative $\bullet \mathrm{OH}$ radicals was also determined in the case of the previously mentioned techniques. As a scavenger of this radical, coumarin was added.
\end{abstract}

Keywords: $\mathrm{TiO}_{2}$-based photocatalysis; Triton X-100; Benzenesulfonic acid; Silver-deposited $\mathrm{TiO}_{2}$; Immobilization; Thermal decomposition of PVA

\section{Introduction}

Nowadays, a great proportion of anthropogenic pollutants cannot be mineralized by traditional biological and physicochemical wastewater treatment procedures. Therefore, important developments in chemical wastewater treatment technologies and in their utilizations are required. For economic, technological and healthcare reasons, in terms of both type and quantity, it is important to use as few chemical additives as possible. Their applicability against remarkably different pollutants using minimal levels of energy consumption is even more important. Advanced Oxidation Processes satisfy these challenges [1]. A common characteristic of these processes is the generation of oxidative radicals, predominantly hydroxyl radicals, using solar radiation or other kinds of energy. Hydroxyl radicals are able to oxidize a great variety of organic compounds, therefore, heterogeneous photocatalysis has become an intensively studied field of research.

In the pharmaceutical industry, benzenesulfonic acid is mostly used for producing other speciality chemicals. A variety of pharmaceutical drugs are prepared as salts of benzenesulfonic acid, known as besilates. Triton X-100

*Correspondence: horvath.otto@mk.uni-pannon.hu with an average $n \approx 9.5$ is one of the most widely applied man-made non-ionic surfactants. Non-ionic surfactants are more stable than ionic tensides and not sensitive to $\mathrm{pH}$ and electrolytes. Besides the hydrophilic polyethoxy chain, it also contains a hydrophobic octylphenyl group. Both compounds can hardly be degraded by biological treatments [2-4]. Hence, a more efficient degradation method like heterogeneous photocatalysis is indispensable for the total mineralization of these pollutants.

\subsection{Photodegradation of model compounds}

The titanium dioxide-mediated photocatalyzed degradation of benzenesulfonic acid (later abbreviated as BS) was investigated by monitoring the absorption and emission spectral changes, sulfate concentration, $\mathrm{pH}$, as well as the total organic carbon (later abbreviated as TOC) content in both argon-saturated and aerated systems.

During the degradation of benzenesulfonic acid, a characteristic change in the $\pi \rightarrow \pi^{*}$ transition (typical of aromatic systems) in the absorption spectrum of BS $\left(\lambda_{\max }=262 \mathrm{~nm}, \varepsilon=439 \mathrm{M}^{-1} \mathrm{~cm}^{-1}\right)$ can be observed. At first, there is a slight increase in the $260-270 \mathrm{~nm}$ range, while two new shoulders appear at around 280 and 300 $\mathrm{nm}$ and as the period of irradiation progresses the level of absorbance decreases. The reason for the increase in absorbance observed in the spectrum of this aromatic surfactant is that the absorbances of the intermediates 
formed in the initial period of the process are higher than that of the starting compound. On the basis of the characteristic molar absorbances of 4hydroxybenzenesulfonic acid (4-HBS) $\left(\lambda_{\max }=277 \mathrm{~nm}\right.$, $\left.\varepsilon=868 \mathrm{M}^{-1} \mathrm{~cm}^{-1}\right)$ and 2,5-dihydroxybenzenesulfonic acid $\left(\lambda_{\max }=302 \mathrm{~nm}, \varepsilon=3300 \mathrm{M}^{-1} \mathrm{~cm}^{-1}\right)$ as commercially available standards, the appearance of a shoulder at 280$300 \mathrm{~nm}$ suggests the formation of hydroxylated intermediates. The results indicate that the initial step of the degradation is hydroxylation of the starting surfactant, resulting in the production of hydroxy- and dihydroxybenzenesulfonates [5-7]. Therefore, liquid chromatography-mass spectrometry analysis was utilized for the detection of intermediates.

The sulfonate group of the substrate to be degraded can easily be oxidized by oxygen-containing reactants generated in these systems. Sulfate ions were detected in the irradiated reaction mixtures, which means that the hydroxylation reactions were accompanied by desulfonation. The initial rate of this process was lower in each case than that for the transformation (i.e. hydroxylation) of the starting compound (BS). These results indicate that the first step of mineralization is hydroxylation; desulfonation takes place afterwards.

During the photocatalytic oxidation of BS, especially in the first $180 \mathrm{~min}$, a continuous decrease of $\mathrm{pH}$ was observed in both the argon-saturated and the aerated systems, i.e. strong acidification occurred. Probably, there is a direct correlation between the formations of hydrogen and sulfate ions, due to the following reaction (Eq.(1)), which can take place between the sulfonate group and hydroxyl radical, the main oxidizing agent in these systems:

$$
\mathrm{RSO}_{3}^{-}+\bullet \mathrm{OH} \rightarrow \mathrm{HSO}_{4}^{-}+\mathrm{R} \bullet \rightarrow \mathrm{H}^{+}+\mathrm{SO}_{4}^{2-}+\mathrm{R} \bullet
$$

The hydroxy species did not decay during the irradiation in the absence of dissolved oxygen. In the aerated system desulfonation and hydroxylation was much more efficient, moreover, a significant decrease in TOC took place during the initial stage. Further hydroxylation resulted in the cleavage of the aromatic system, through the formation of polyhydroxy derivatives, followed by ring-opening, which led to the production of aldehydes and carboxylic acids. Total mineralization was realized by the end of the photocatalysis. It has been proved that in this photocatalytic procedure the presence of dissolved oxygen is indispensable for the cleavage of the aromatic ring because hydroxyl radicals photochemically formed in the deaerated system alone are not able to break the C-C bond [5].

The degradation mechanism of Triton X-100 was also investigated [8]. In the case of this surfactant, hydroxyl radicals can attack in three ways; on the ethoxy chain, on the aromatic ring or on the alkyl chain. According to the absorption spectrum (no shift in the longer wavelength $(275 \mathrm{~nm})$ band and no new shoulders), no hydroxylation of the aromatic ring took place during the photocatalytic degradation. After the total disappearance of the starting surfactant (after approx. $60 \mathrm{~min}$ ), an appreciable degree of absorbance arose at $275 \mathrm{~nm}$, which indicates that aromatic intermediates were formed during the first hour. In liquid chromatographic experiments, Triton X-100 produced a multiple-peaked chromatogram. The retention time of these non-ionic surfactant components is in strong correlation with the length of the ethoxy chain. Intermediates formed from various lengths of ethoxy chains and others with aromatic rings were detected in the reaction mixture after irradiation started. The concentration of the shorter-chain molecules increased during the initial stage (in the first $10 \mathrm{~min}$ ) of the irradiation, indicating that the fragmentation of the longer polyethoxy chains of the starting components initially increased the concentration of those with shorter ones, which was followed by a gradual decay. The component with a relative molecular weight of 206 Dalton could be clearly identified. Based on its structure, it was identified as the alkyl phenol part of the original Triton X-100. Its concentration peaked at around the 50th minute of irradiation. This is the result of the total cleavage of the polyethoxy chains without any oxidation of the rest of the original tenside molecules. Based on the results so far, it can be stated that hydroxyl radicals attack the ethoxy side-chain and subsequently the alkyl group, afterwards, the ring opens.

\subsection{Challenges of heterogeneous photocatalysis}

The obstacle to the practical application of heterogeneous photocatalysis is that its efficiency is relatively low. Fortunately there are several ways to improve its mineralization effect: by the combination of heterogeneous catalysis with other oxidative procedures such as ozonation $[6,9-10]$ or by the modification of the catalyst with precious metals. The latter solution helps promote charge separation by accumulating the electrons on the surface of the silver particles [11-12].

The other obstacle is that the catalyst is in a suspended form, therefore, its separation from the liquid phase is difficult and makes the technology more expensive. This problem can be eliminated if the catalyst is immobilized. There are several methods for immobilization, for example, the catalyst particles can be fixed directly into polymers. Between a polymer and the catalyst usually a physical contact is formed, but in some cases, such as with poly(vinyl alcohol), a chemical bond can be formed. Unfortunately, this method is not free of disadvantages. The fact that immobilization decreases the active surface area of the catalyst has to be taken into consideration, thus, it will become less efficient [13-16].

Irradiation in the near UV range generates electron-hole pairs in the $\mathrm{TiO}_{2}$ nanoparticles. Under aerobic conditions the electrons in the conduction band are scavenged by adsorbed oxygen molecules with a relatively high quantum yield, producing $\mathrm{O}_{2} \bullet^{-}$ions, which are readily protonated in acidic media. Beides, 
the holes, in the absence of reducing species, oxidize the surface-adsorbed water or hydroxide ions to hydroxyl radicals. The $\cdot \mathrm{OH}$ radical can also be formed by thermal reactions following the primary electron transfer processes that occur at the surface of semiconductor particles or in the liquid phase $[13,17]$.

The hydroxyl radical is often assumed to be the major reactant responsible for the photooxidation of various organic molecules. The first step of the mineralization of benzenesulfonic acid is hydroxylation of the aromatic ring, while the degradation of Triton $\mathrm{X}$ 100 is initialized by hydroxyl radicals, which attack the ethoxyl side chain (Fig. 1).

Due to the high reactivity and short lifetime of $\cdot \mathrm{OH}$, the direct detection of this species is difficult. Appropriate methods such as steady-state fluorescence were applied to measure the quantity of scavenged hydroxyl radicals. Recent studies have proved that several non- or weakly luminescent test molecules, such as coumarin, produce strongly luminescent compounds (7-hydroxycoumarin) with hydroxyl radicals. Thus, these molecules can be utilized for detecting and measuring $\cdot \mathrm{OH}$ radicals produced by $\mathrm{UV}$ excitation of $\mathrm{TiO}_{2}$ particles in heterogeneous systems [18-19].

The main goal of our work was to investigate the effect of silver doping and immobilization of the catalyst applied for photocatalytic degradations. In this work, coumarin was used as a scavenger to determine the formation rate of hydroxyl radicals under various circumstances.

\section{Experimental section}

\subsection{Materials}

For the experiments, the following materials were used: benzenesulfonic acid $\left(\mathrm{C}_{6} \mathrm{H}_{5} \mathrm{O}_{3} \mathrm{~S}\right.$ - Alfa Aesar), 4hydroxybenzenesulfonic acid $\left(\mathrm{C}_{6} \mathrm{H}_{4}(\mathrm{OH}) \mathrm{O}_{3} \mathrm{~S}\right.$ - Alfa Aesar), silver nitrate $\left(\mathrm{AgNO}_{3}-\right.$ Aldrich), Degussa P25 $\mathrm{TiO}_{2}: 25 \pm 5 \%$ rutile, $75 \pm 5 \%$ anatase with a specific surface area of $50 \mathrm{~m}^{2} \mathrm{~g}^{-1}$ (now called Evonik AEROXIDE® $\left.\mathrm{TiO}_{2} \mathrm{P} 25\right)$, coumarin $\left(\mathrm{C}_{9} \mathrm{H}_{6} \mathrm{O}_{2}\right.$ - VWR), Triton X-100 $\left(\mathrm{C}_{14} \mathrm{H}_{22} \mathrm{O}\left(\mathrm{C}_{2} \mathrm{H}_{4} \mathrm{O}\right)_{9.5}\right.$ - Alfa Aesar), and poly(vinyl alcohol) ((later abbreviated as PVA) $\mathrm{M}=146000-186000 \mathrm{~g} \mathrm{~mol}{ }^{-1}$, hydrolysis: $99+\%$ Aldrich). The materials used for the HPLC and IC measurements were the following: methanol $\left(\mathrm{CH}_{3} \mathrm{OH}\right.$ Sigma-Aldrich), tetra-n-butylammonium bromide $\left(\left(\mathrm{CH}_{3} \mathrm{CH}_{2} \mathrm{CH}_{2} \mathrm{CH}_{2}\right)_{4} \mathrm{NBr}\right.$ - Sigma-Aldrich), sodium sulfate $\left(\mathrm{Na}_{2} \mathrm{SO}_{4}-\mathrm{VWR}\right), 37 \%$ cc. hydrochloric acid ( $\mathrm{HCl}$ - VWR) and sodium hydroxide (NaOH - VWR). High purity water, used in this study as a solvent, was double distilled and then purified using a Milli-Q system.

\subsection{Analytics}

For the analysis, $4 \mathrm{~cm}^{3}$ samples were taken, the solid phase was removed by filtration using Millipore MillexLCR PTFE $0.45 \mu \mathrm{m}$ filters. The absorption spectral

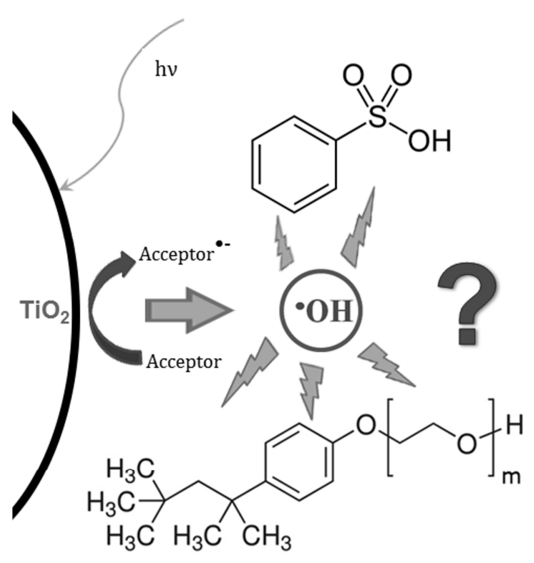

Figure 1 . The role of $\bullet \mathrm{OH}$ radicals in the degradation of the model compounds.

changes of the reaction mixtures irradiated were followed using a PerkinElmer Lambda $25 \mathrm{UV}-\mathrm{Vis}$ spectrophotometer, while the emission spectra were recorded using a PerkinElmer LS 50B spectrofluorometer. Both measurements were carried out in $1 \mathrm{~cm}$ quartz cuvettes. Mineralization was followed by measuring the total organic carbon (TOC) concentration, utilizing a Thermo Electron Corporation TOC TN 1200 apparatus. The $\mathrm{pH}$ of the aqueous phase of the reaction mixture was determined by a SP10T electrode connected to a Consort C561 instrument.

HPLC analyses of the benzenesulfonic acid samples were carried out using an Agilent 1100 instrument. A water:methanol (in a volume ratio of 95:5) solvent mixture containing $0.1 \%(\mathrm{v} / \mathrm{v})$ formic acid was the mobile phase with a flow rate of $1 \mathrm{~cm}^{3}$ $\mathrm{min}^{-1}$. During the experiments a $100 \times 2 \mathrm{~mm}$ Synergi Hydro-RP C18 (Phenomenex, Torrance, CA, USA) column packed with $2.5 \mu \mathrm{m}$ particles was used. The column was thermostated at $30^{\circ} \mathrm{C}$. The sample volume injected was $1 \mu \mathrm{l}$, photometric detection was applied at wavelengths of 262, 277 and $302 \mathrm{~nm}$.

Degradation of Triton X-100 was followed by the 1290 Infinity UHPLC system (Agilent Technologies Inc., Santa Clara, CA, USA). The mobile phase was 65:35 methanol:water for five minutes of analysis, then it was gradually increased to 75:25 over the following five minutes. The signal was detected with a DAD detector. The column used during the experiments was a $100 \times 2 \mathrm{~mm}$ Synergi Hydro-RP C18 (Phenomenex, Torrance, CA, USA) column packed with $2.5 \mu \mathrm{m}$ particles. The column was thermostated at $50{ }^{\circ} \mathrm{C}$. The flow rate of the eluent was $1 \mathrm{~cm}^{3} \mathrm{~min}^{-1}$.

During the study of the degradation mechanism an Agilent $6890 \mathrm{~N}$ gas chromatograph with an Agilent DB$5 \mathrm{~ms}$ Ultra Inert column $(30 \mathrm{~m} \times 0.25 \mathrm{~mm} \times 250 \mu \mathrm{m})$ was used for the separation. As a detector, an Agilent 5973 N-type mass spectrometer was used.

The surface of immobilized catalysts was tested using a Philips/FEI XL30 scanning electron microscope at an accelerating voltage of $20 \mathrm{kV}$, using backscattered electron imaging. The composition was measured by an EDAX Genesis energy dispersive X-ray analyzer. Prior to testing, the samples were sputter coated by a $10 \mathrm{~nm}$ 
thick layer of gold. Elements of the qualitative composition do not overlap with the gold, therefore, the gold coating did not disturb the analysis.

\subsection{Experimental circumstances}

The concentration of benzenesulfonic acid to be degraded was $10^{-3} \mathrm{M}$ in each experiment, while that of the catalyst was $1 \mathrm{~g} \mathrm{dm}^{-3}$ in all cases. For homogenization, the suspension was stirred for 20 minutes in the reactor before irradiation. The silverdeposited $\mathrm{TiO}_{2}$ was prepared by photoreduction from a mixture initially containing $10^{-4} \mathrm{M} \mathrm{AgNO}_{3}$ and $1 \mathrm{~g} \mathrm{dm}^{-3}$ $\mathrm{TiO}_{2}$ as a photocatalyst. After 1 hour of photoreduction the catalyst, brown in color, was separated by vacuum filtration then dried at room temperature. To re-suspend the catalyst powder before each experiment an ultrasonic bath was applied in order to achieve a dispersion of particles sufficiently small in size. During subsequent ultrasonic treatment, the substrate to be degraded was added to the system only after a period of time, so that the $\bullet \mathrm{OH}$ radicals generated during the sonication could recombine and not tamper with the experimental results.

A detailed description of the production of immobilized catalyst can be found in our previous article [20]. The PVA- $\mathrm{TiO}_{2}$ catalyst was prepared by using a PVA with a molecular weight of 146 000-186 000 and a $99+\%$ degree of hydrolysis and Degussa P-25 $\mathrm{TiO}_{2}$. Immobilization was carried out using a solutioncasting method [21]. The PVA-TiO 2 mixture was stirred at 90 then $60^{\circ} \mathrm{C}$, subsequently a viscous solution was obtained, which was then poured into a petri dish and dried. The average weight of the immobilized catalyst was $0.47 \mathrm{~g}$ with a PVA content of $40 \%$. Before its use, it was subjected to a 2 hour-long thermal treatment in an argon atmosphere to increase its stability. The Triton X100 concentration was $2 \cdot 10^{-4} \mathrm{M}$ with $1.5 \mathrm{~g} \mathrm{dm}^{-3} \mathrm{TiO}_{2}$. It is important to note that when comparing the efficiencies of the catalyst in various forms, the amount of $\mathrm{TiO}_{2}$ immobilized in PVA $(0.3 \mathrm{~g})$ and used as a suspension in $200 \mathrm{~cm}^{3}$ of reaction mixture were both 1.5 $\mathrm{g} \mathrm{dm}^{-3}$.

Photochemical experiments were carried out using two different reactors and light-source setups.

One was a laboratory-scale reactor with an effective volume of $2.5 \mathrm{dm}^{3}$, equipped with a $40 \mathrm{~W}$ light tube located in the middle of the reactor. It emitted most of its energy at wavelengths exceeding $300 \mathrm{~nm}$ $\left(\lambda_{\max }=350 \mathrm{~nm}\right.$, i.e. within the UVA range) [5]. The photon flux of the light source was $\mathrm{I}_{0}=4.3 \cdot 10^{-6} \mathrm{~mol}$ photon $\mathrm{dm}^{-3} \mathrm{~s}^{-1}$, which was measured by the actinometry of trisoxalatoferrate(III). The heterogeneous reaction mixture was circulated by using a peristaltic pump through the reactor and a buffer vessel. Compressed air was bubbled through the reaction mixtures from gas bottles, to facilitate stirring and (with its $\mathrm{O}_{2}$ content) as an electron acceptor. $\mathrm{O}_{3}$ was produced by a LAB2B ozone generator, and introduced into the same airstream. The ozone concentration was determined by iodometry, using sodium iodide as a

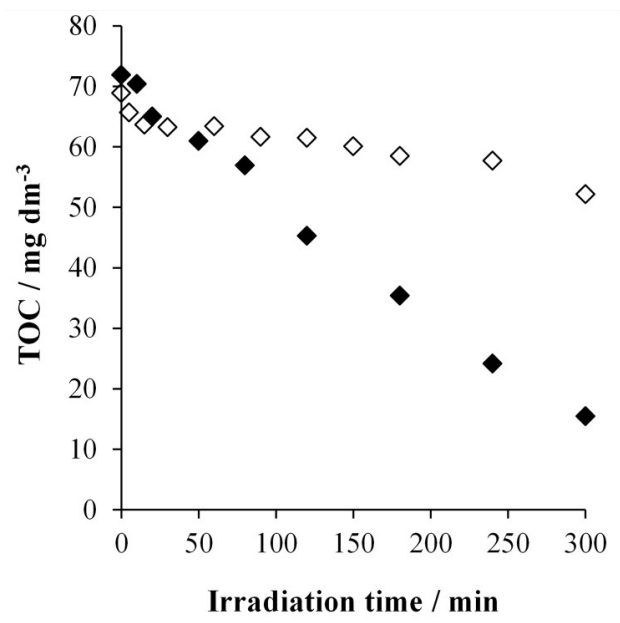

Figure 2. Change in the TOC concentration in the case of two different light sources used for irradiation. $\mathrm{c}(\mathrm{BS})_{0}=10^{-3} \mathrm{M}$, air: $40 \mathrm{dm}^{3} \mathrm{~h}^{-1}, \mathrm{c}\left(\mathrm{TiO}_{2}\right)=1 \mathrm{~g} \mathrm{dm}^{-3}$

$\diamond-$ air $+\mathrm{TiO}_{2}+$ solar simulator

- air+ $\mathrm{TiO}_{2}+\mathrm{UV}$ lamp

reagent and sodium thiosulfate for the titration of the iodine formed. The ozone dosage was estimated to be $0.35 \mathrm{mM} \mathrm{min}^{-1}$.

The other setup consisted of one small reactor made of borosilicate glass (its volume was $250 \mathrm{~cm}^{3}$ ) [20]. The catalyst film was placed on a perforated glass platform (foil holder) standing on a glass frit, through which compressed air was bubbled from a gas bottle at a flow rate of $10 \mathrm{dm}^{3} \mathrm{~h}^{-1}$, ensuring a constant oxygen concentration. The $200 \mathrm{~cm}^{3}$ reaction mixture (Triton X100 solution or distilled water in the case of pretreatment) was circulated by a magnetic stirrer. It was irradiated from above using an Oriel LCS-100 solar simulator resulting in a light intensity of $72 \mathrm{~mW} \mathrm{~cm}$ on the surface of the reaction mixture.

Fig. 2 shows the change in TOC during the photodegradation of benzenesulfonic acid under various experimental conditions. The band-gap energy of $\mathrm{TiO}_{2}$ is $3.2 \mathrm{eV}$, indicating that the catalyst can be excited by light of $360 \mathrm{~nm}$ in wavelength. The difference between the two light sources used is clearly visible. The radiation intensity of the solar simulator in the UV range is very low, so the total organic carbon content of the initial solution decreased by only $10 \mathrm{mg}$ over 360 minutes, while total mineralization was achieved using the UV lamp within this period.

\section{Results}

\subsection{Increase in photocatalytic efficiency using various methods}

As mentioned previously, the efficiency of heterogeneous photocatalysis can be increased in multiple ways: by combination with other oxidative procedures such as ozonation and by modification of the catalyst surface using noble metals.

Since the first reaction in the mechanism of photocatalytic oxidative degradation of benzenesulfonic 
acid is hydroxylation of the aromatic ring, the determination of the rates of formation of hydroxyl radicals as the main oxidant in these systems was indispensable as far as the elucidation of the mechanism under various circumstances was concerned. Coumarin was used as an $\bullet \mathrm{OH}$ scavenger.

An intensive band at $278 \mathrm{~nm}$ and a shoulder at around $300 \mathrm{~nm}$ is visible in the absorption spectrum of coumarin. The level of absorbance quickly decreased under irradiation (Fig.S1), while the concentration of the fluorescent 7-hydroxycoumarin rapidly increased during the initial period, and subsequently decreased gradually, i.e. degraded (Fig.S2). By depicting the intensity of the emission line at $453 \mathrm{~nm}$ as functions of the irradiation time, the initial rate of formation of 7 hydroxycoumarin, which is proportional to that of the hydroxyl radicals formed, can be determined from the initial gradients of the increasing sections, so it is easy to compare the ability of each process to generate hydroxyl radicals [18].

Before measuring the formation of 7hydroxycoumarin in the photocatalytic oxidative systems that apply ozone, blind probes were used (Fig.3). The reaction between coumarin and ozone in the dark (at $10^{-4} \mathrm{M}$ coumarin and $0.35 \mathrm{mM} \mathrm{min}^{-1}$ ozone concentrations) yielded a negligible spectral change after 2 hours. Although ozone itself is a strong oxidant, a very low rate of formation of 7-hydroxycoumarin (0.32 INT $\left.\mathrm{min}^{-1}\right)$ was observed under these experimental conditions. Upon UV irradiation of this probe, the rate of formation slightly increased (to 1.84 INT $\min ^{-1}$ ).

Ozone can be absorbed over a wide range, from infrared to vacuum UV, but is optimal at $254 \mathrm{~nm}$. The light source applied in this work emits most of its radiation in the 300-380 $\mathrm{nm}$ range, where the molar absorbances of $\mathrm{O}_{3}$ are rather low. Thus, it can poorly promote the dissociation of ozone via the homolytic cleavage of a bond.

Contrary to the blind probe with ozone, significant spectral changes were observed in irradiated reaction

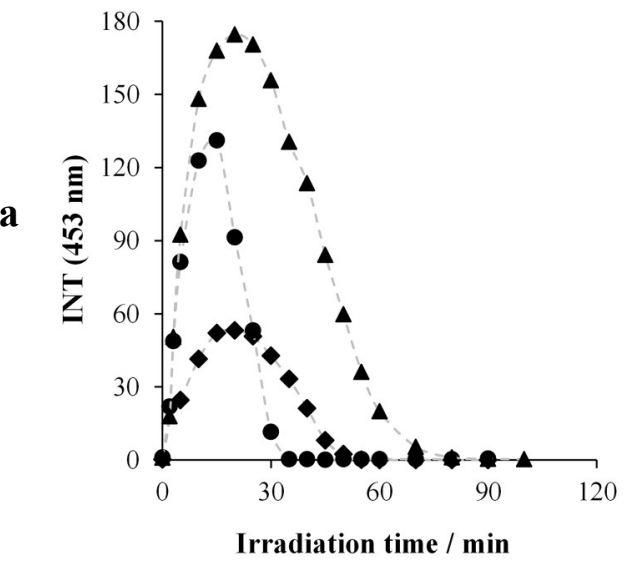

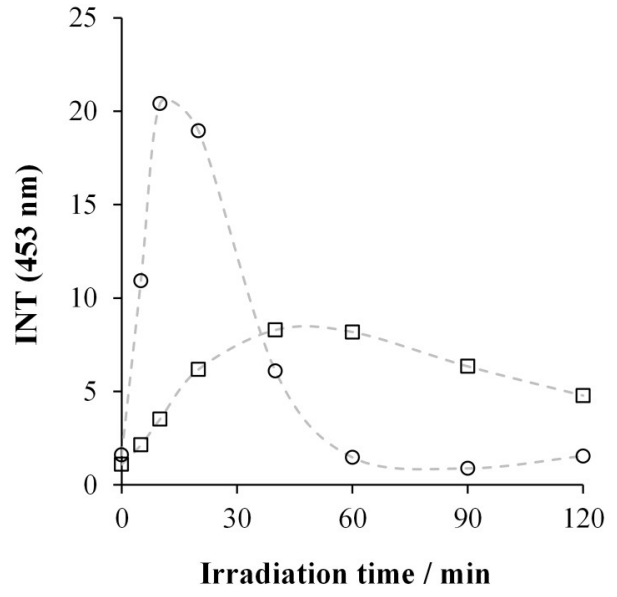

Figure 3. Change in the luminescence intensity of 7-hydroxycoumarin formed $\left(\lambda_{\text {exc }}=332 \mathrm{~nm}\right)$. c(coumarin $)_{0}=10^{-4} \mathrm{~mol} \mathrm{dm}^{-3}$, air: $40 \mathrm{dm}^{3} \mathrm{~h}^{-1}, \mathrm{c}\left(\mathrm{O}_{3}\right)=0.35 \mathrm{mM}$, $\ell=1 \mathrm{~cm}$

$\square-\mathrm{O}_{3} \quad \mathrm{O}-\mathrm{O}_{3}+\mathrm{UV}$

mixtures containing catalysts. The surface of the catalyst was also modified with silver and combined with ozonation, then the difference between the effects of the two methods of improvement was investigated by determining the rate of formation of oxidative $\cdot \mathrm{OH}$ radicals (Fig.4).

The combination of heterogeneous photocatalysis with ozonation resulted in a 2.5 fold increase in the rate of formation (from 7.42 INT $\mathrm{min}^{-1}$ to $19.4 \mathrm{INT} \mathrm{min}^{-1}$ ). A further increase was achieved by the application of surface-modified (silver-deposited) titanium dioxide (to 21.9 INT $\mathrm{min}^{-1}$ ). These results are in accordance with the fact that silver deposited on the surface of the catalyst diminishes the probability of the recombination of the photogenerated electron-hole pair, i.e. promotes charge separation [11].

\subsubsection{Degradation of benzenesulfonic acid}

Our research group has been studying the combination

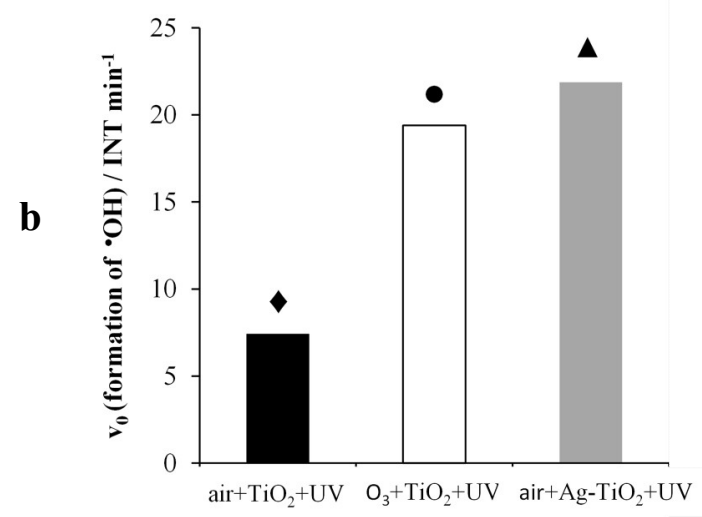

Figure 4. Change in the luminescence intensity of 7-hydroxycoumarin produced $\left(\lambda_{\text {exc }}=332 \mathrm{~nm}\right)$ (a) and rates of formation of $\bullet \mathrm{OH}$ radicals under various circumstances (b). $\mathrm{c}(\text { coumarin })_{0}=10^{-4} \mathrm{~mol} \mathrm{dm}{ }^{-3}$, air: $40 \mathrm{dm}^{3} \mathrm{~h}^{-1}, \mathrm{c}\left(\mathrm{O}_{3}\right)=0.35 \mathrm{mM}, \mathrm{c}$ (catalyst $)=1 \mathrm{~g} \mathrm{dm}^{-3}, \ell=1 \mathrm{~cm}$ - - air $+\mathrm{TiO}_{2}+\mathrm{UV} \bullet-\mathrm{O}_{3}+\mathrm{TiO}_{2}+\mathrm{UV} \quad \boldsymbol{\Delta}-\mathrm{air}+\mathrm{Ag}-\mathrm{TiO}_{2}+\mathrm{UV}$ 
Table 1. Comparison of the initial rates*.

\begin{tabular}{|c|c|c|}
\cline { 2 - 3 } \multicolumn{1}{c|}{} & TOC & $\begin{array}{c}\text { Benzenesulfonic } \\
\text { acid }\end{array}$ \\
\cline { 2 - 3 } & {$\left[\mathrm{mg} \mathrm{d} \mathrm{m}^{-3} \mathbf{~ m i n}^{-1}\right]$} & {$\left[\mathbf{m M ~ \mathbf { m i n } ^ { - 1 } ]}\right.$} \\
\hline \hline $\begin{array}{c}\text { air+ } \\
\mathbf{A g - T i O}\end{array}$ & $1.58 \cdot 10^{-1}$ & $2.3 \cdot 10^{-2}$ \\
\hline $\mathbf{a i r}+\mathbf{T i O}_{2}+\mathbf{U V}$ & $2.24 \cdot 10^{-1}$ & $6.5 \cdot 10^{-3}$ \\
\hline $\mathbf{O}_{3}+\mathbf{T i O}_{2}+\mathbf{U V}$ & $5.92 \cdot 10^{-1}$ & $1.3 \cdot 10^{-2}$ \\
\hline
\end{tabular}

of heterogeneous photocatalysis and ozonation in detail. It has been established that a joint application of these procedures results in synergic effects [6].

Another possibility of enhancing the efficiency of photocatalysis is the modification of the catalyst surface by the deposition of silver. Our results in this work are compared with previous observations [17].

The spectral changes during the irradiations of suspensions containing $\mathrm{Ag}-\mathrm{TiO}_{2}$ agree with earlier results. The degree of light absorption increases during the initial period (until the 50th minute), then it decreases (Fig.S3). The fine-band structure gradually disappears, while new bands arise at longer wavelengths (277 and $302 \mathrm{~nm}$ ), suggesting the formation of isomers of hydroxy- and dihydroxybenzenesulfonic acid [6].

Characteristic changes can also be observed in the emission spectra of the samples in these experiments: an increase in the intensity of luminescence for 60 minutes, then a decrease accompanied by a red-shift of the 290 $\mathrm{nm}$ band (characteristic of the starting compound) and the appearance of a new emission band at about $330 \mathrm{~nm}$ (Fig.S4). The band-shift becomes considerable (46.5 $\mathrm{nm})$ after the first hour of irradiation: from $286 \mathrm{~nm}$ to $333 \mathrm{~nm}$. This finding also confirms the formation of hydroxy and dihydroxy intermediates with $\lambda_{\text {em.max. }}=305$ $\mathrm{nm}$ and $352 \mathrm{~nm}$, respectively.

The changes in the concentrations of benzenesulfonic acid and the hydroxylated intermediates were followed by HPLC analyses (Fig.5). Of the three possible hydroxy isomers, the absolute concentration could only be determined for the commercially available 4-hydroxybenzenesulfonic acid (4-HBS, $\mathrm{rt}=0.86 \mathrm{~min}$ ).

Although the concentration of the substrate gradually decreases, the content of the benzenesulfonic acid in the reaction mixture is practically zero by the 180th minute of irradiation. On the basis of the concentration vs. time plot, the rate of decay of the model compound was determined by polynomial fit: $2.1 \cdot 10^{-2} \mathrm{mM} \mathrm{min}^{-1}$. Regarding the heterogeneous catalytic experiments (untreated $\mathrm{TiO}_{2}$ catalyst), $8 \cdot 10^{-3}$ $\mathrm{mM} \min ^{-1}$ was the degradation rate of the starting surfactant, while $1.4 \cdot 10^{-2} \mathrm{mM} \mathrm{m^{-1 }}$ was measured in the case of combination with ozonation (Table 1) [6].

Mineralization of the model compound was followed by TOC (total organic carbon content) measurements. Taking the difference between the TOC value of the reaction mixture (TOC of the solution) and that of the benzenesulfonic acid (TOC of BS, calculated from its actual concentration), the TOC value regarding

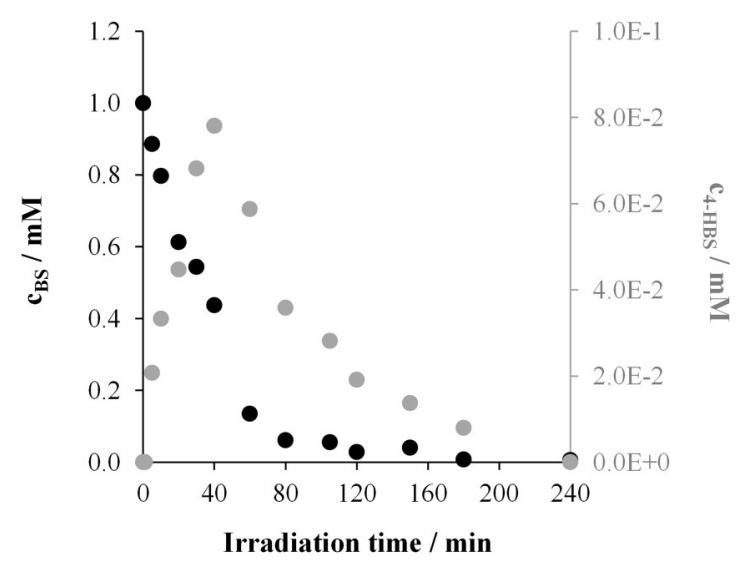

Figure 5. Transformation of the initial compound and change in concentration of the 4-HBS intermediate. $\mathrm{c}(\mathrm{BS})_{0}=10^{-3} \mathrm{M}$, air: $40 \mathrm{dm}^{3} \mathrm{~h}^{-1}, \mathrm{c}\left(\mathrm{Ag}-\mathrm{TiO}_{2}\right)=1 \mathrm{~g} \mathrm{dm}^{-3}$

the intermediates in the solution can be obtained (Fig. 6). This figure also displays the TOC values belonging to 4-HBS (calculated from its actual concentrations, see Fig.5)

The concentration of the starting material and its TOC value rapidly decrease in the heterogeneous photocatalytic experiments involving silver-modified $\mathrm{TiO}_{2}$, while the amount of intermediates (predominantly hydroxy and dihydroxy derivatives) gradually increases. The initial rate of decrease in TOC for the reaction mixture was $1.58 \cdot 10^{-1} \mathrm{mg} \mathrm{dm}^{-3} \mathrm{~min}^{-1}$.

The first step of the degradation of the model compound is hydroxylation. The highest initial rate of decay of BS was observed in the case of the system containing the silver-modified catalyst (Fig. 7, Table 1). These results are in good agreement with those obtained for the experiments using coumarin, an efficient scavenger of $\bullet \mathrm{OH}$. The highest initial rate of formation of hydroxyl radicals was obtained on the $\mathrm{Ag}-\mathrm{TiO}_{2}$

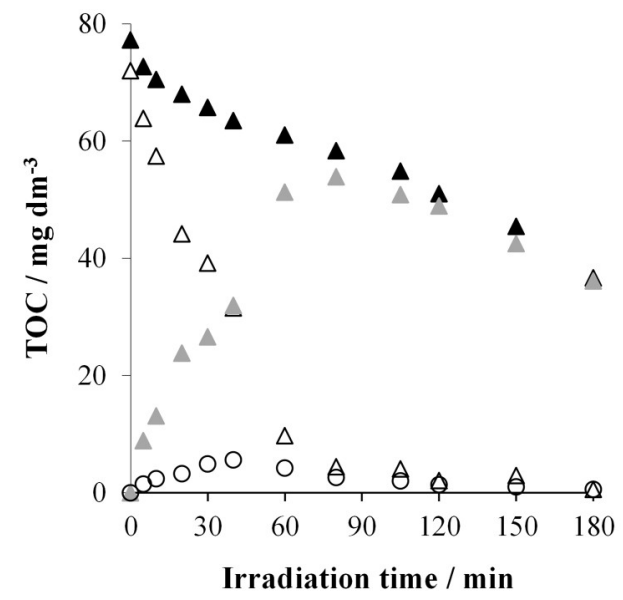

Figure 6. Change in TOC contents during the treatment.

$\mathrm{c}(\mathrm{BS})_{0}=10^{-3} \mathrm{M}$, air: $40 \mathrm{dm}^{3} \mathrm{~h}^{-1}, \mathrm{c}\left(\mathrm{Ag}-\mathrm{TiO}_{2}\right)=1 \mathrm{~g} \mathrm{dm}^{-3}$

$\Delta-$ TOC of the solution (measured)

$\triangle-$ TOC of BS (calculated)

$\triangle-$ TOC of intermediates (calculated)

O - TOC of 4-HBS (calculated)

catalyst. 

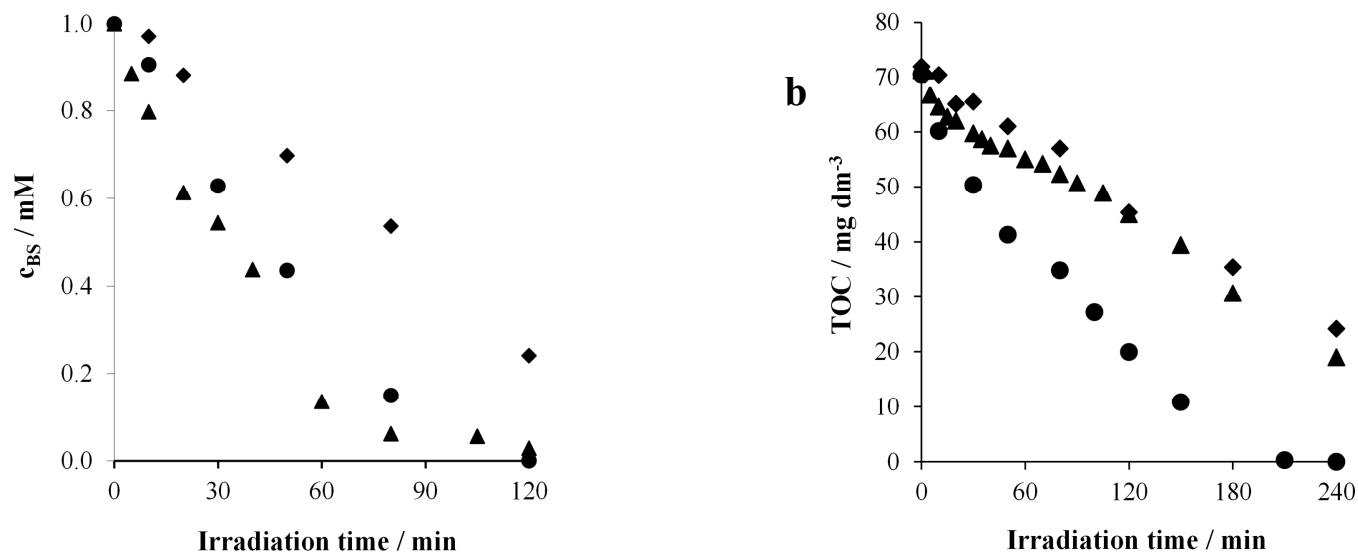

Figure 7. Change in concentrations of BS (a) and TOC (b) under various circumstances. $\mathrm{c}(\mathrm{BS})_{0}=10^{-3} \mathrm{M}$, air: $40 \mathrm{dm}^{3} \mathrm{~h}^{-1}, \mathrm{c}\left(\mathrm{O}_{3}\right)=0.35 \mathrm{mM}, \mathrm{c}$ (catalyst $)=1 \mathrm{~g} \mathrm{dm}^{-3}$

- - air $+\mathrm{TiO}_{2}+\mathrm{UV} \bullet-\mathrm{O}_{3}+\mathrm{TiO}_{2}+\mathrm{UV} \quad \boldsymbol{\Delta}-\mathrm{air}+\mathrm{Ag}-\mathrm{TiO}_{2}+\mathrm{UV}$

The cleavage of the aromatic ring is indispensable in terms of the mineralization of the model compound, besides the fragmentation of the hydrocarbon chain. Szabó-Bárdos et al. rendered it probable that ringopening takes place in the reaction of hydroxylated intermediates with reactive oxygen-containing species $\left(\mathrm{O}_{2}{ }^{-} / \mathrm{HO}_{2} \bullet, \mathrm{O}_{2}\left({ }^{1} \Delta \mathrm{g}\right)\right)$ [5]. Deviating from the decrease in the $\mathrm{BS}$ concentration, the lowest rate of the decrease in TOC, an indicator of mineralization, was observed in the case of the silver-modified catalyst, while the highest value (3.7 times higher than the previous one) was obtained for the combined procedure (Fig.7, Table $1)$.

Based on our results, the application of heterogeneous photocatalysis with silver-modified $\mathrm{TiO}_{2}$ only accelerates the formation of hydroxyl radicals, while its combination with ozonation also increases the amount of other oxidative radicals $\left(\mathrm{O}_{2^{\bullet}}{ }^{-} / \mathrm{HO}_{2}{ }^{\bullet}, \mathrm{O}_{2}\left({ }^{1} \Delta \mathrm{g}\right)\right)$.

\subsection{Immobilization of the catalyst with poly(vinyl alcohol)}

The thermal treatment of the immobilized catalysts, the preparation of which was thoroughly described in
Section 2.3, resulted in significant physical and chemical changes; on the one hand, their thickness varied (Fig.8), on the other hand, their color turned from their original white to brown (Fig.9). Song et al. described similar results [22].

The thickness of the foils prepared was tested by scanning electron microscopy prior to and after the thermal treatment. Following the treatment, the average thickness decreased from about $75.6 \mu \mathrm{m}$ to about 69.6 $\mu \mathrm{m}$ (Fig.8). The shrinkage of about $6 \mu \mathrm{m}$ can be attributed to the evaporation of water content.

It has been established in our earlier studies that during the thermal treatment the polymer underwent dehydroxylation and cracking processes; compounds containing double and triple bonds as well as aromatic rings appeared on the surface of the foil, increasing its degree of light absorption [20]. Irradiation of the immobilized catalysts in the absence of the model compound led to the dissolution of the side-products of the cracking processes, and they also underwent heterogeneous photocatalytic degradation due to the presence of $\mathrm{TiO}_{2}$. Accordingly, stearic acid and its derivatives containing double bonds such as linoleic acid (9,12-octadecadienoic acid (Z,Z)- and oleic acid (9octadecanoic acid) were detected by GC-MS analysis of

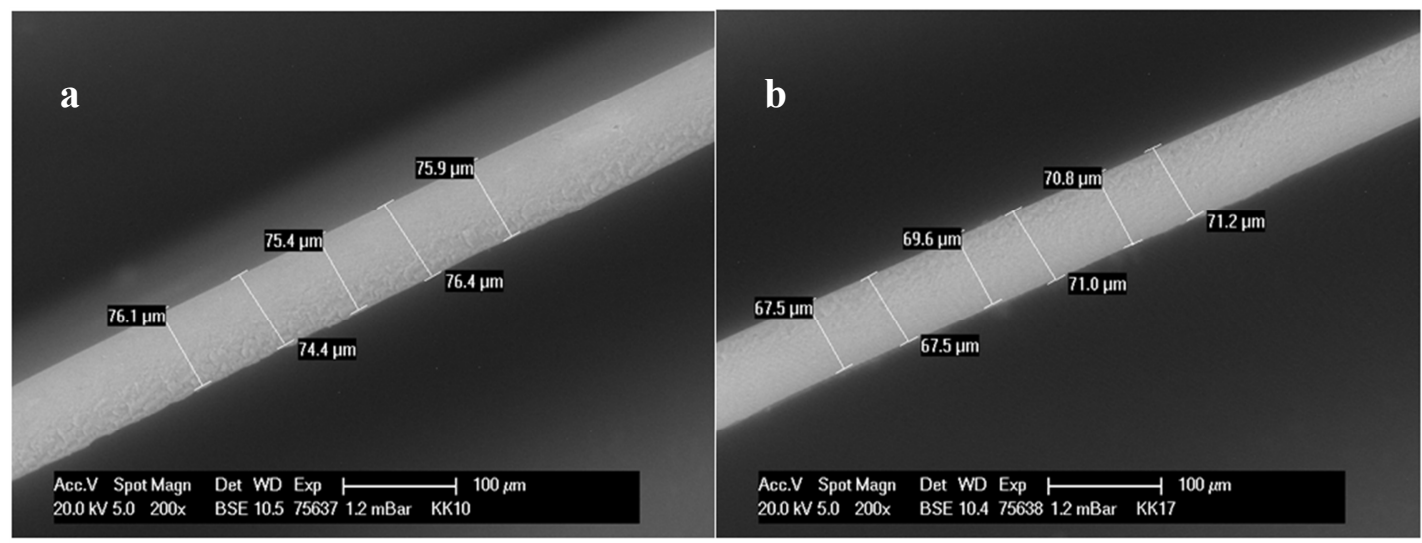

Figure 8. Cross sections of scanning electron micrographs of $\mathrm{PVA}^{-\mathrm{TiO}_{2}}$ foils before (a) and after (b) thermal treatment. 
the liquid phase. During the photocatalytic degradation, organic acids with shorter hydrocarbon chains were also produced, e.g. tetradecanoic acid (C14), caprylic acid (C8) and malic acid (C4) [20]. Although thermal treatment improves the stability of the foil, it restricts its efficiency because a considerable proportion of the oxidative radicals formed during photocatalysis are consumed in the reactions with the pollutants produced during the thermal treatment. Taking all these factors into consideration, how the temperature of the thermal treatment affects the stability of the immobilized catalyst was also studied.

The foils heated at different temperatures were submersed in $200 \mathrm{~cm}^{3}$ of distilled water, then irradiated for 8 hours. The change in TOC of the liquid phase is shown in Fig. 10/a, while the reductions in the foil masses are displayed in Fig. 10/b. For the interpretation of the results, the increase in the temperature of the solution due to irradiation also has to be taken into account, because it enhances the solubility of poly(vinyl alcohol), i.e. the amount of the dissolved PVA, which increases the actual TOC value. The organic materials (PVA and the products of the thermal treatment) dissolved off the foil which also underwent photocatalytic degradation in the presence of $\mathrm{TiO}_{2}$. Both processes determine the change in TOC in the liquid phase, along with the mass reduction of the foil. The stability of the foils treated at lower temperatures (e.g. at $60^{\circ} \mathrm{C}$ ) is rather modest, the PVA is dissolved in water, the TOC value of the liquid phase increased to $130 \mathrm{mg}$ $\mathrm{dm}^{-3}$ by the end of the experiment, and the mass of the foil decreases considerably. The stability of the foils treated at higher temperatures (e.g. at $140^{\circ} \mathrm{C}$ or $200^{\circ} \mathrm{C}$ ) significantly increased, while the TOC value of the liquid phase only grew slightly (to $34 \mathrm{mg} \mathrm{dm}^{-3}$ at $140^{\circ} \mathrm{C}$, to $18 \mathrm{mg} \mathrm{dm}^{-3}$ at $200^{\circ} \mathrm{C}$ ), in a similar fashion to the weight loss of the foils $\left(140^{\circ} \mathrm{C}-\Delta \mathrm{m}=93 \mathrm{mg}, 200^{\circ} \mathrm{C}-\right.$ $\Delta \mathrm{m}=24 \mathrm{mg}$ ).

The results clearly indicate that by increasing the temperature of the thermal treatment, the stability of the foil is gradually improved, due to efficient crosslinking [21]. The thermally treated immobilized catalysts cannot be applied for photocatalytic purposes, because they undergo degradation themselves during the irradiation, increasing the TOC value of the solution

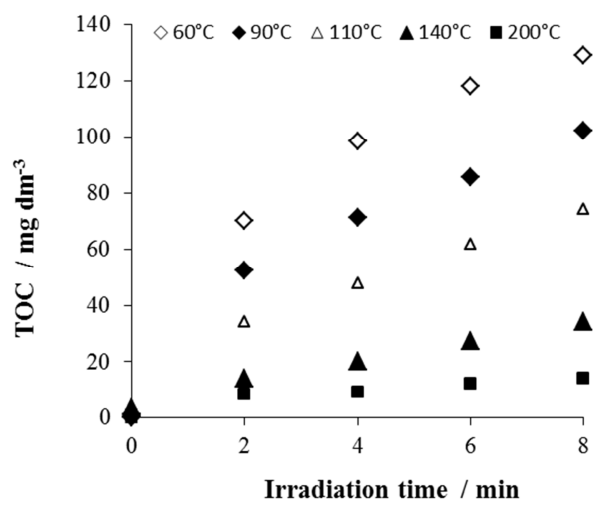

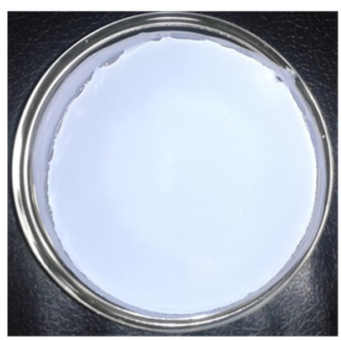

Before heat treatment

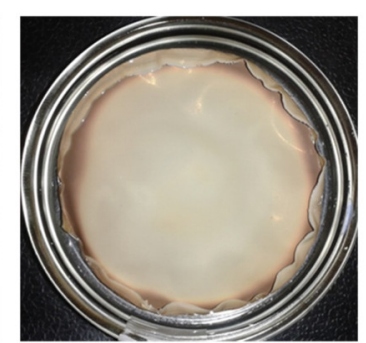

After heat treatment
Figure 9. Immobilized catalysts before and after heat treatment.

phase. Besides, the brownish organic compounds formed in the cracking processes diminish the catalytic efficiency because they occupy the active sites on the catalyst surface. Hence, a compromise has to be made between stability and efficiency. Efforts were made to mineralize the products of cracking during a pretreatment. Before the photocatalytic experiments, the thermally treated foils were cleaned by three sequential 8-hour-long pre-treatments, to remove the pollutants formed during the cracking processes. Since the pollutants formed whilst heated at the higher temperature $\left(200^{\circ} \mathrm{C}\right)$ were rather difficult to remove, $140^{\circ} \mathrm{C}$ was applied for the thermal treatment of the foils in further experiments of ours [20].

\subsubsection{Efficiency of $\bullet \mathrm{OH}$ production during pre- treatments of immobilized catalysts}

To detect the hydroxyl radicals formed during the irradiation of $\mathrm{TiO}_{2}$ particles embedded in the polymer, $10^{-4} \mathrm{M}$ of coumarin as a scavenger was applied. Following the thermal treatment to enhance the stability of the foils, the undesirable products of this procedure have to be removed. In the first cycle of this process, when the foil is yet brown, the immobilized photocatalyst starts to work upon irradiation, but oxidative radicals formed in this process are mostly involved in the degradation of the products of cracking. The initial rate for the formation of 7-hydroxycoumarin just slightly exceeds the value observed in blind experiments (in the absence of a catalyst); $3 \cdot 10^{-2}$ INT $\min ^{-1}$ (blind), $4 \cdot 10^{-2}$ INT $\min ^{-1}$ (1st cycle) (Fig. 11).

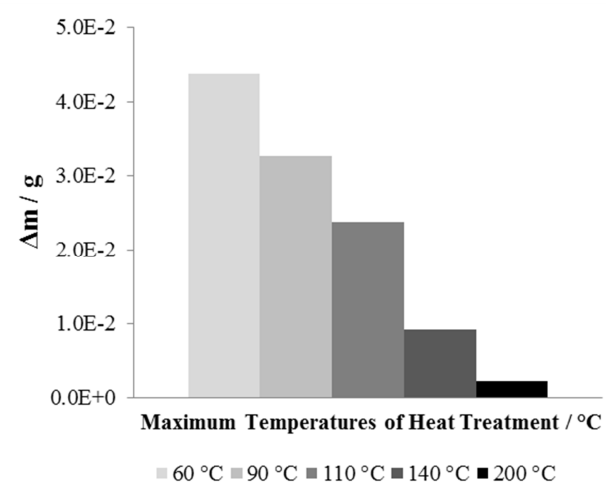

Figure 10. Change in the TOC content of the liquid phase after various heat treatments (a) and the weight loss of foils after 8 hours of irradiation (b) $200 \mathrm{~cm}^{3}$ distilled water, air: $10 \mathrm{dm}^{3} \mathrm{~h}^{-1}, \mathrm{c}\left(\mathrm{TiO}_{2}\right)=1.5 \mathrm{~g} \mathrm{dm}^{-3}$

Hungarian Journal of Industry and Chemistry 
b

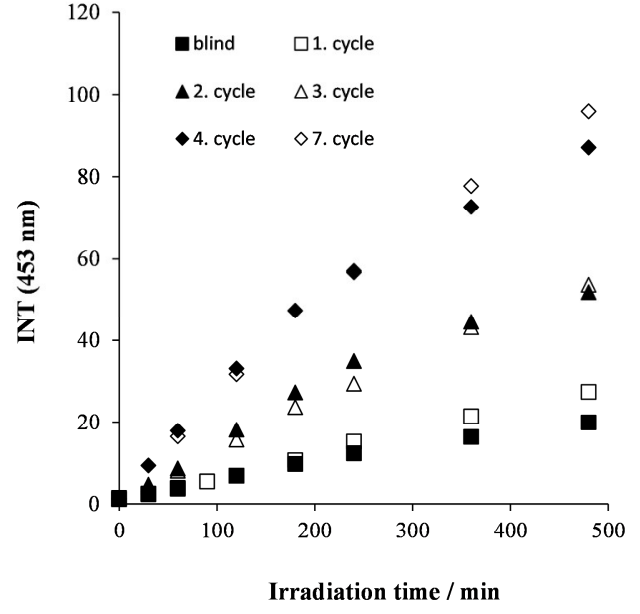

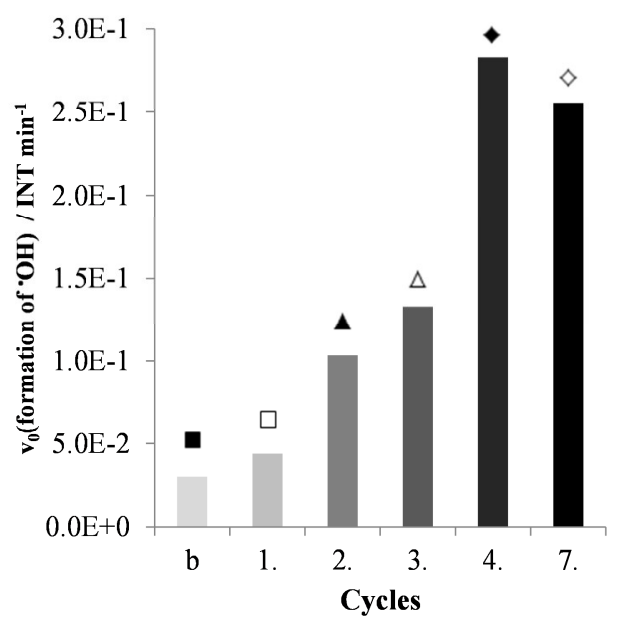

Figure 11. Change in the intensity of luminescence of 7-hydroxycoumarin formed. c (coumarin $)_{0}=10^{-4} \mathrm{M}$, air: $10 \mathrm{dm}^{3} \mathrm{~h}^{-1}, \lambda_{\text {exc }}=332 \mathrm{~nm}$

The rate of formation of the hydroxyl radicals significantly increases during the 2nd cycle; the emission intensity at the end of this cycle $\left(\mathrm{v}_{0}=10^{-1}\right.$ INT $\left.\mathrm{min}^{-1}\right)$ is more than twice as high as in the previous one. The results obtained during the 3 rd cycle are similar to those during the 2nd one. Practically, during the three sequential 8-hour-long periods of irradiation, the polluting compounds that originate from the thermal treatment are totally degraded, hence, the active sites on the surface of the catalyst become more accessible, resulting in a much higher rate for the formation of oxidative radicals (in the 4 th cycle $\mathrm{v}_{0}=2.5-2.8 \cdot 10^{-1}$ INT $\mathrm{min}^{-1}$, see Fig.11). In other applications, the radical producing efficiency of the catalyst does not change significantly, i.e. the foil can be applied at constant efficacy. The lower value determined during the 7 th cycle suggests a slow rate of degradation of the immobilized catalyst, which has to be taken into consideration during its application.

\subsubsection{Degradation of the model compound}

The photocatalytic degradation of the model compound was investigated following the cleaning procedure. The average degree of degradation of Triton X-100 in three sequential cycles was $62 \%$; the deviations might originate from measurement errors (Fig. 12). This value is significantly lower than that observed in the case of the suspended catalyst (90\%). Although the catalyst concentrations with regard to the volume of solution were equal $\left(1.5 \mathrm{~g} \mathrm{dm}^{-3}\right)$, immobilization considerably diminished the specific surface of the catalyst, leading to a substantial decrease in its efficiency. Mineralization of Triton X-100 takes place via cleavage-producing intermediates. The cleavage of the alkyl-phenyl part of the starting components of Triton X-100 took place from the beginning of the irradiation period. As completive intermediates originated from such a cleavage, ethylene glycol and dioxolane derivatives were detected by GC-MS. At the beginning of the irradiation the edge of the starting molecules or the initially generated intermediates mineralize to $\mathrm{CO}_{2}$. Therefore, the decrease in TOC is much less than expected from the concentration change. The concentration changes of Triton X-100 components and the typical intermediates are in accordance with our previous results using a similar system that applied a suspended catalyst (see section 1.1). Remarkably, GCMS analyses did not detect any intermediates which might derive from the PVA support. This suggested that three pre-treatment cycles of irradiation and rinsing were sufficient for a satisfactory level of removal of the derivatives formed during the thermal treatment.

\subsubsection{Surface morphology of foils - SEM analysis}

The behavior of the active surface of immobilized photocatalysts after repeated use raises an important issue. The surfaces of titanium dioxide containing PVA before and after thermal treatment are shown in Figs. 13/a and 13/b, respectively. Some $\mathrm{TiO}_{2}$-rich islands (Fig.14) are not fully covered by the PVA film, these are visible on the surface. Otherwise, no significant changes are observed after the thermal treatment. However, simulated solar radiation (repeated usage) induces visible changes in the morphology of the

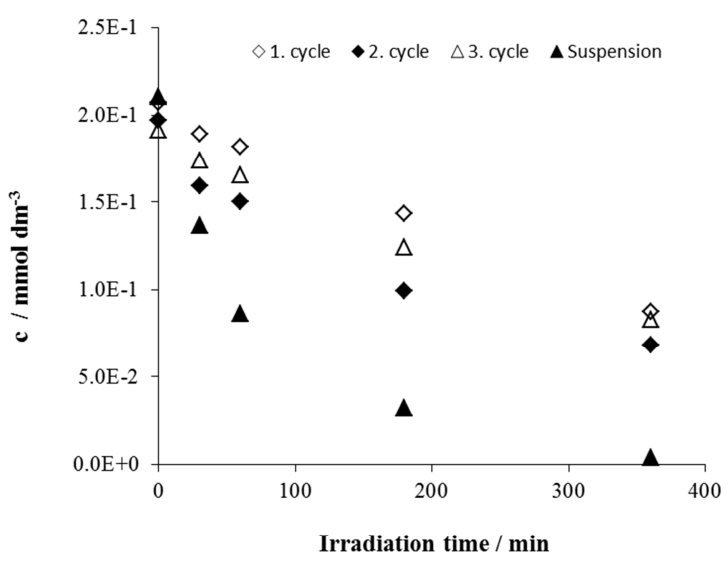

Figure 12. Change in concentration change of Triton $\mathrm{X}-100$ during the irradiation. $\mathrm{c}(\mathrm{TX}-100)_{0}=2 \cdot 10^{-4} \mathrm{M}$, air: $10 \mathrm{dm}^{3} \mathrm{~h}^{-1}, \mathrm{c}\left(\mathrm{TiO}_{2}\right)=1.5 \mathrm{~g} \mathrm{dm}^{-3}$ 

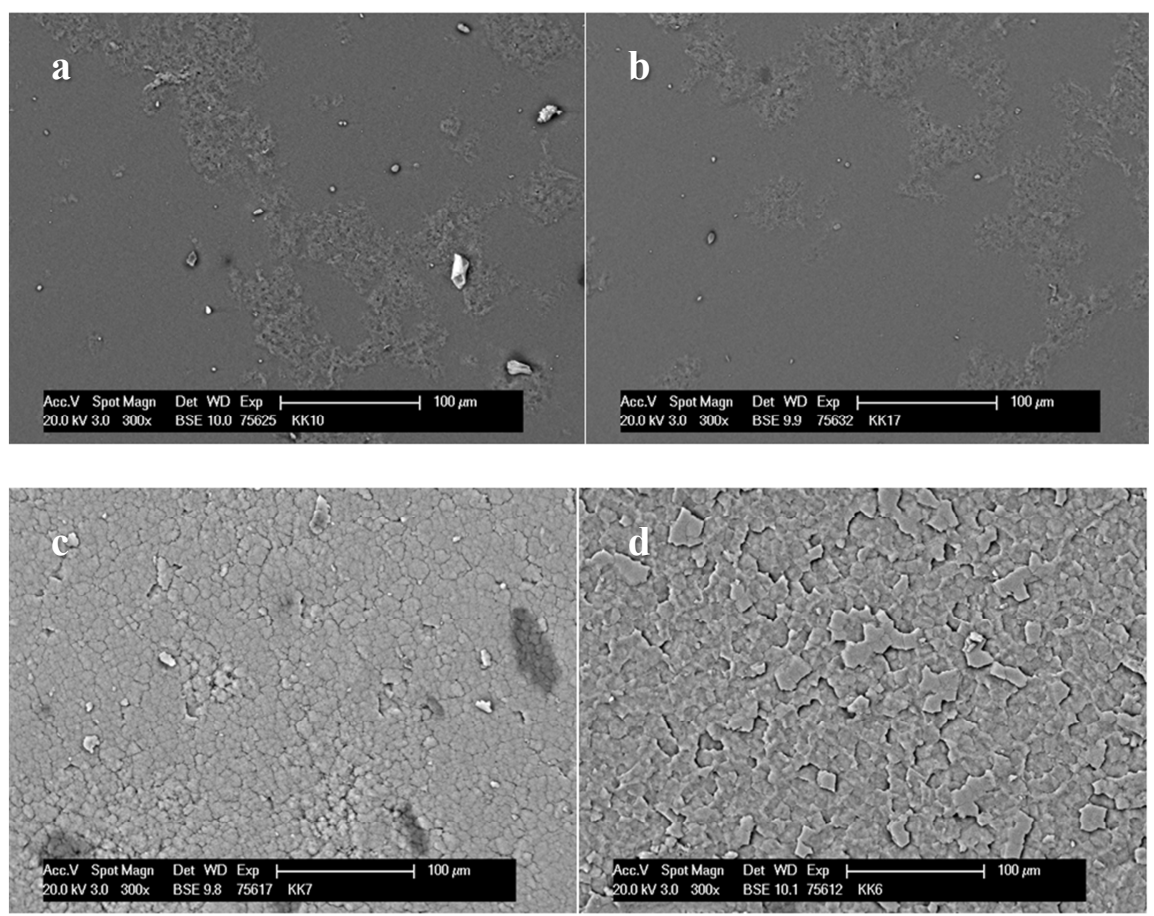

Figure 13. Scanning electron micrographs of foil surfaces.

a) before and b) after thermal treatment c) after 4 irradiation cycles d) after 7 cycles of irradiation

surface. Such a period of radiation partially or totally removes the PVA layer covering the $\mathrm{TiO}_{2}$ agglomerates. This process is enhanced after prolonged use: after four cycles the homogeneously distributed particles are already visible (Fig.13/c). Extended use - seven cycles will enhance grain boundaries by removing more of the PVA matrix, indeed some of the particles become loosely bounded to the rest of the agglomerate (Fig.13/d). The observed changes in thickness strongly correlate with the degradation of films (Fig.15). After four cycles, a significant decrease in thickness can be observed: the foil thickness decreases to about $58.5 \mu \mathrm{m}$ (from $69.6 \mu \mathrm{m}$ ). This corresponds to a decrease of about $2.7 \mu \mathrm{m} /$ cycle. As for the thickness measured after seven cycles, the last three cycles only represent a decrease of about $0.9 \mu \mathrm{m} /$ cycle. These observations imply a more intense degree of degradation during the initial stage.

\section{Conclusion}

Heterogeneous photocatalytic procedures are widely applied for the degradation of organic pollutants. The degradation of benzenesulfonic acid and Triton X-100 by heterogeneous photocatalysis was investigated under various circumstances. The formation of hydroxyl radicals as one of the major reactants responsible for the photooxidation of these molecules was also measured in the case of both setups of the catalyst.

Silver deposition on the surface of the $\mathrm{TiO}_{2}$ catalyst significantly increased the initial degradation (hydroxylation) rate of $\mathrm{BS}$, due to the hindered recombination of the photogenerated electron-hole pairs, increasing the rate of $\bullet \mathrm{OH}$ production. However, mineralization of the intermediates was not accelerated by this method, deviating from the combination of the $\mathrm{TiO}_{2}$-based photocatalysis with ozonation. The degradation efficiency in the latter procedure indicated a synergic effect on the mineralization rate as a consequence of the enhanced production of oxidative agents other than $\bullet \mathrm{OH}$ radicals [6]. These reactive oxidants play key roles in the ring-opening processes needed for the mineralization of aromatic intermediates. Quantitative determinations of such reactants (e.g. $\mathrm{O}_{2}{ }^{-}$ and $\left.\mathrm{O}_{2}\left({ }^{1} \Delta_{\mathrm{g}}\right)\right)$ to gain a deeper understanding of the mineralization mechanism are in progress. Our results indicate that the methods applied for the enhancement of the degradation efficiency in heterogeneous photocatalysis affect the generation of the oxidizing agents in different ways, which ought to be taken into consideration in further studies.

In general, suspensions of the photocatalyst are used in these procedures. Thus, at the end of these processes the semiconductor particles have to be separated from the cleaned solution. This operation can be taken out by immobilization of the catalyst, which was achieved by using poly(vinyl alcohol) in this work.

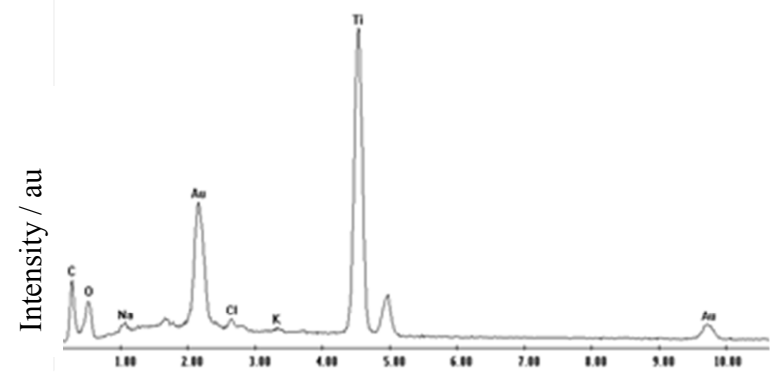

Figure 14. Energy dispersive X-Ray spectra of the $\mathrm{TiO}_{2}$ island. 


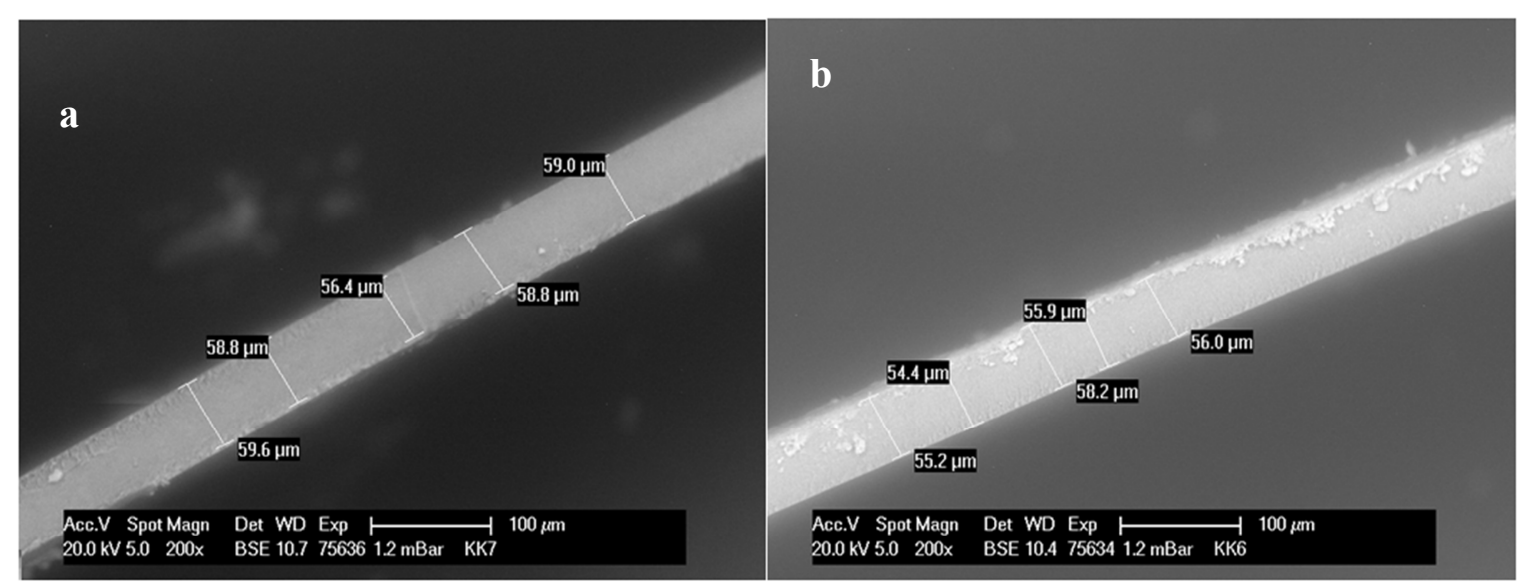

Figure 15. Scanning electron micrographs of cross sections of film. a) after 4 cycles of irradiation b) after 7 cycles of irradiation.

The stability of the PVA support proved to be too low for practical use. The stability of the PVA-based foils could be considerably improved by thermal treatment. However, before photocatalytic application the watersoluble products of the heating process had to be removed from the surface of the $\mathrm{PVA}_{-} \mathrm{TiO}_{2}$ foil. According to the efficiency of $\bullet \mathrm{OH}$ formation, three cycles of irradiation and rinsing proved to be sufficient for this purpose. The foil pre-treated by this method could be applied for the photocatalytic degradation of a frequently used non-ionic detergent, Triton X-100. When using the immobilized catalyst, it should be noted that the foil catalyst is degraded, its thickness decreases and the catalyst particles become more and more accessible on the surface.

\section{Acknowledgements}

This work was supported by Széchenyi 2020 under the projects GINOP-2.3.2-15-2016-00016 and EFOP-3.6.116-2016-00015.

\section{REFERENCES}

[1] Dewil, R.; Mantzavinos, D.; Poulios, I.; Rodrigo, M. A.: New perspectives for Advanced Oxidation Processes, J. Environ. Manage., 2017195 93-99 DOI: 10.1016/j.jenvman.2017.04.010

[2] Hack, N.; Reinwand, C.; Abbt-Braun, G.; Horn, H.; Frimmel, F. H.: Biodegradation of phenol, salicylic acid, benzenesulfonic acid, and iomeprol by Pseudomonas fluorescens in the capillary fringe, J. Contam. Hydrol., 2015183 40-54 DOI: 10.1016/j.jconhyd.2015.10.005

[3] Mohan, P. K.; Nakhla, G.; Yanful, E. K.: Biokinetics of biodegradation of surfactants under aerobic, anoxic and anaerobic conditions, Water Res., $2006 \quad 40(3) \quad 533-540 \quad$ DOI: 10.1016/j.watres.2005.11.030
[4] Wyrwas, B.; Dymaczewski, Z.; ZgołaGrześkowiak, A.; Szymański, A.; Frańska, M.; Kruszelnicka, I.; Ginter-Kramarczyk, D.; Cyplik, P.; Ławniczak, Ł.; Chrzanowski, Ł.: Biodegradation of Triton X-100 and its primary metabolites by a bacterial community isolated from activated sludge, J. Environ. Manage., 2013128 292-299 DOI: 10.1016/j.jenvman.2013.05.028

[5] Szabó-Bárdos, E.; Markovics, O.; Horváth, O.; Törö, N.; Kiss, G.: Photocatalytic degradation of benzenesulfonate on colloidal titanium dioxide, Water Res., 2011 45(4) 1617-1628 DOI: 10.1016/j.watres.2010.11.045

[6] Zsilák, Z.; Szabó-Bárdos, E.; Fónagy, O.; Horváth, O.; Horváth, K.; Hajós, P.: Degradation of benzenesulfonate by heterogeneous photocatalysis combined with ozonation, Catal. Today, 2014230 55-60 DOI: 10.1016/j.cattod.2013.10.039

[7] Zsilák, Z.; Fónagy, O.; Szabó-Bárdos, E.; Horváth, O.; Horváth, K.; Hajós, P.: Degradation of industrial surfactants by photocatalysis combined with ozonation, Environ. Sci. Pollut. Res., 2014 21(19) 11126-11134 DOI: 10.1007/s11356-014-2527-2

[8] Hegedűs, P.; Szabó-Bárdos, E.; Horváth, O.; Horváth, K.; Hajós, P.: $\quad \mathrm{TiO}_{2}$-mediated photocatalytic mineralization of a non-ionic detergent: Comparison and combination with other advanced oxidation procedures, Materials (Basel)., 2015 8(1) 231-250 DOI: 10.3390/ma8010231

[9] Rodríguez, E. M.; Márquez, G.; León, E. A.; Álvarez, P. M.; Amat, A. M.; Beltrán, F. J.: Mechanism considerations for photocatalytic oxidation, ozonation and photocatalytic ozonation of some pharmaceutical compounds in water, $J$. Environ. Manage., $2013 \quad 127 \quad 114-124$ DOI: 10.1016/j.jenvman.2013.04.024

[10]Agustina, T. E.; Ang, H. M.; Vareek, V. K.: A review of synergistic effect of photocatalysis and ozonation on wastewater treatment, J. Photochem. Photobiol. C Photochem. Rev., 2005 6(4) 264-273 DOI: 10.1016/j.jphotochemrev.2005.12.003 
[11]Szabó-Bárdos, E.; Czili, H.; Horváth, A.: Photocatalytic oxidation of oxalic acid enhanced by silver deposition on a TiO 2 surface, $J$. Photochem. Photobiol. A., 2003154 195-201 DOI: 10.1016/S1010-6030(02)00330-1

[12]Ma, J.; Guo, X.; Zhang, Y.; Ge, H.: Catalytic performance of $\mathrm{TiO}_{2} @ \mathrm{Ag}$ composites prepared by modified photodeposition method, Chem. Eng. J., 2014258 247-253 DOI: 10.1016/j.cej.2014.06.120

[13]Chong, M. N.; Jin, B.; Chow, C. W. K.; Saint, C.: Recent developments in photocatalytic water treatment technology: A review, Water Res., 2010 44(10) 2997-3027 DOI: 10.1016/j.watres.2010.02.039

[14]Gar Alalm, M.; Tawfik, A.; Ookawara, S.: Enhancement of photocatalytic activity of $\mathrm{TiO}_{2}$ by immobilization on activated carbon for degradation of pharmaceuticals, J. Environ. Chem. Eng., 2016 4(2) 1929-1937 DOI: 10.1016/j.jece.2016.03.023

[15]Bouarioua, A.; Zerdaoui, M.: Photocatalytic activities of $\mathrm{TiO}_{2}$ layers immobilized on glass substrates by dip-coating technique toward the decolorization of methyl orange as a model organic pollutant, J. Environ. Chem. Eng., 2017 5(2) 15651574 DOI: 10.1016/j.jece.2017.02.025

[16]Veréb, G.; Ambrus, Z.; Pap, Z.; Mogyorósi, K.; Dombi, A.; Hernádi, K.: Immobilization of crystallized photocatalysts on ceramic paper by titanium(IV) ethoxide and photocatalytic decomposition of phenol, React. Kinet. Mech. Catal., 2014 113(1) 293-303 DOI: 10.1007/s11144-0140734-y
[17]Kondrakov, A. O.; Ignatev, A. N.; Lunin, V. V.; Frimmel, F. H.; Bräse, S.; Horn, H.: Roles of water and dissolved oxygen in photocatalytic generation of free $\mathrm{OH}$ radicals in aqueous $\mathrm{TiO}_{2}$ suspensions: An isotope labeling study, Appl. Catal. B Environ., 2016182 424-430 DOI:10.1016/j.apcatb.2015.09.038

[18]Czili, H.; Horváth, A.: Applicability of coumarin for detecting and measuring hydroxyl radicals generated by photoexcitation of $\mathrm{TiO}_{2}$ nanoparticles, Appl. Catal. B Environ., 2008 81(3-4) 295-302 DOI:10.1016/j.apcatb.2008.01.001

[19] Ishibashi, K. I.; Fujishima, A.; Watanabe, T.; Hashimoto, K.: Detection of active oxidative species in $\mathrm{TiO}_{2}$ photocatalysis using the fluorescence technique, Electrochem. commun., 2000 2(3) 207-210 DOI:10.1016/S1388-2481(00)00006-0

[20]Hegedűs, P.; Szabó-Bárdos, E.; Horváth, O.; Szabó, P.; Horváth, K.: Investigation of a $\mathrm{TiO}_{2}$ photocatalyst immobilized with poly(vinyl alcohol), Catal. Today., $2017 \quad 284$ 179-186 DOI:10.1016/j.cattod.2016.11.050

[21]Lei, P.; Wang, F.; Gao, X.; Ding, Y.; Zhang, S.; Zhao, J.; Liu, S.; Yang, M.: Immobilization of $\mathrm{TiO}_{2}$ nanoparticles in polymeric substrates by chemical bonding for multi-cycle photodegradation of organic pollutants, J. Hazard. Mater., 2012 227-228 185-194 DOI:10.1016/j.jhazmat.2012.05.029

[22] Song, Y.; Zhang, J.; Yang, H.; Xu, S.; Jiang, L.; Dan, Y.: Preparation and visible light-induced photo-catalytic activity of H-PVA/TiO2 composite loaded on glass via sol-gel method, Appl. Surf. Sci., $2014 \quad 292 \quad 978-985$ DOI: 10.1016/j.apsusc.2013.12.090 